
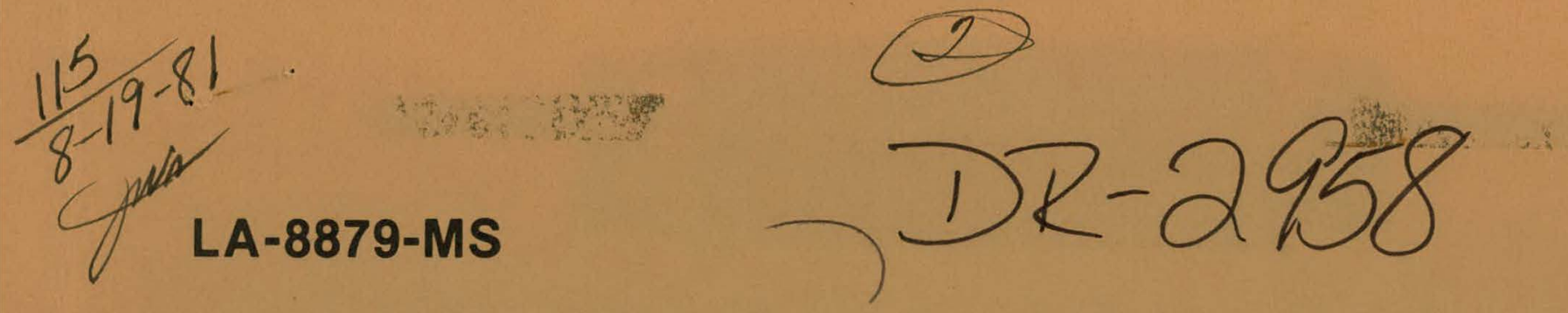

Los Names Matinnal I aberatory is operated by the University of California for the United States Department of Energy under contract W-7405-ENG-36.

$$
365^{2}
$$

\title{
A Comment on S-Matrix Parameterizations in NN-Scattering
}




\section{DISCLAIMER}

This report was prepared as an account of work sponsored by an agency of the United States Government. Neither the United States Government nor any agency Thereof, nor any of their employees, makes any warranty, express or implied, or assumes any legal liability or responsibility for the accuracy, completeness, or usefulness of any information, apparatus, product, or process disclosed, or represents that its use would not infringe privately owned rights. Reference herein to any specific commercial product, process, or service by trade name, trademark, manufacturer, or otherwise does not necessarily constitute or imply its endorsement, recommendation, or favoring by the United States Government or any agency thereof. The views and opinions of authors expressed herein do not necessarily state or reflect those of the United States Government or any agency thereof. 


\section{DISCLAIMER}

Portions of this document may be illegible in electronic image products. Images are produced from the best available original document. 
Edited by Helen M. Sinoradzki

Photocomposition by Kristine Mathieson and Joni L. Powell

This report was prepared as an account of work sponsored by an agency of the United States Government. Neither the United States Government nor any agency thereof, nor any of their employees, makes any warranty, express or implied, or assumes any legal liability or responsibility for the accuracy, completeness, or usefulness of any information, apparatus, product, or process disclosed, or represents that its use would not infringe privately owned rights. References herein to any specific commercial product, process, or service by trade name, trademark, manufacturer, or otherwise, does not necessarily constitute or imply its endorsement, recommendation, or favoring by the United States Government or any agency thereof. The views and opinions of authors expressed herein do not necessarily state or reflect those of the United States Government or any agency thereof. 


\section{A Comment on S-Matrix Parameterizations in $\mathrm{NN}$-Scattering}

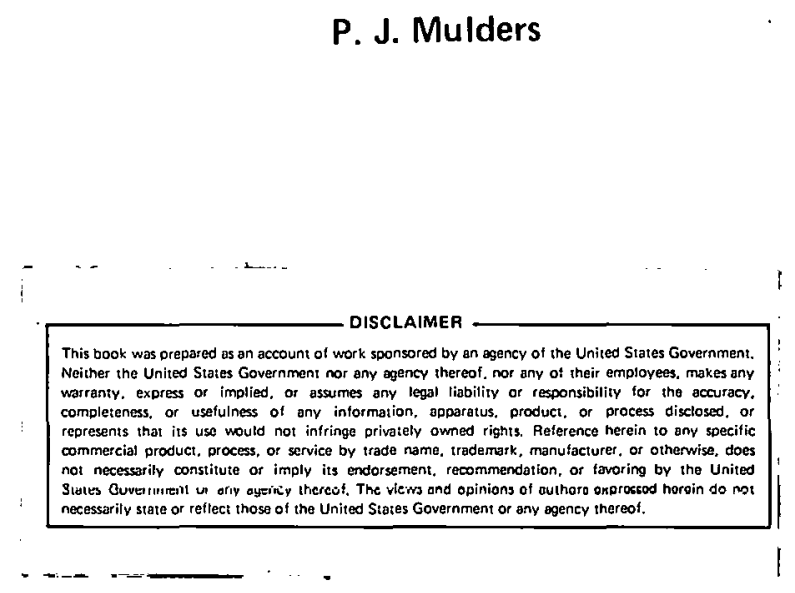




\section{A COMMENT ON S-MATRIX PARAMETERIZATIONS IN NN-SCATTERING}

by

\section{P. J. Mulders}

\section{ABSTRACT}

The parameterization of the S-matrix used for the elastic part of the $\mathrm{NN}$-scattering matrix in, for example, the Virginia Polytechnic Institute interactive nucleon-nucleon program SAID, is not general enough to parameterize any 2 by 2 submatrix of a unitary matrix.

The choice of parameters in parameterizations of the S-matrix in NN-scattering is significant. When only the NN channels are considered, the S-matrix is one- or two-dimensional. For $\mathrm{N}$ channels, the $\mathrm{N}$ by $\mathrm{N}$ unitary symmetric $\mathrm{S}$-matrix is determined by $\mathrm{N}(\mathrm{N}+1) / 2$ parameters. The commonly used parameterizations in $\mathrm{NN}$-scattering are

$$
\underline{N}=1: \quad S=e^{21 \delta} .
$$

To avoid ambiguities, the range of the parameter $\delta$, the phase shift, is restricted to $0 \leqq \delta<\pi$.

$$
\begin{aligned}
N=2: \quad \mathrm{S} & =\left(\begin{array}{cc}
\cos \varepsilon & -\sin \varepsilon \\
\sin \varepsilon & \cos \varepsilon
\end{array}\right)\left(\begin{array}{ll}
\mathrm{e}^{2 \mathrm{i} \delta_{1}} & 0 \\
0 & \mathrm{e}^{2 \mathrm{i} \delta_{2}}
\end{array}\right)\left(\begin{array}{cc}
\cos \varepsilon & \sin \varepsilon \\
-\sin \varepsilon & \cos \varepsilon
\end{array}\right) \\
& =\left(\begin{array}{ll}
\cos 2 \bar{\varepsilon} \mathrm{e}^{2 \mathrm{i} \bar{\delta}_{1}} & \mathrm{i} \sin 2 \varepsilon \mathrm{e}^{\mathrm{i}\left(\bar{\delta}_{1}+\bar{\delta}_{2}\right)} \\
\mathrm{i} \sin 2 \bar{\varepsilon} \mathrm{e}^{\mathrm{i}\left(\bar{\delta}_{1}+\bar{\delta}_{2}\right)} & \cos 2 \bar{\varepsilon} \mathrm{e}^{2 \mathrm{i} \bar{\delta}_{2}}
\end{array}\right) .
\end{aligned}
$$

In Eq. (2a), $\delta_{1}$ and $\delta_{2}$ are the eigenphase shifts. The phase shifts in Eq. (2b) are the nuclear bar phase shifts. ${ }^{1}$ The relations between the parameters are

$$
\begin{aligned}
& \bar{\delta}_{1}+\bar{\delta}_{2}=\delta_{1}+\delta_{2}, \\
& \sin 2 \bar{\varepsilon}=\sin 2 \varepsilon \sin \left(\delta_{1}+\delta_{2}\right), \text { and } \\
& \sin \left(\bar{\delta}_{1}-\bar{\delta}_{2}\right)=\frac{\tan 2 \bar{\varepsilon}}{\tan 2 \varepsilon} .
\end{aligned}
$$

The range for the 8 's is $0 \leqq \delta<\pi$; fur llie aingles $\varepsilon$ it is $-\pi / 4<c \leqq \pi / 4$. 
When scattering into several inelastic channels occurs, the one- or two-dimensional elastic part of the symmetric S-matrix is a 1 by 1 or 2 by 2 complex symmetric matrix. Then the unitarity of the whole $S$ matrix requires at least

$$
\left|s_{11}\right| \leqq 1
$$

for the uncoupléd NN-channel, or

$$
\begin{aligned}
& \left|S_{11}\right|^{2}+\left|S_{12}\right|^{2} \leqq 1 \\
& \left|S_{21}\right|^{2}+\left|S_{22}\right|^{2} \leqq 1
\end{aligned}
$$

for the coupled NN-channel.

For the uncoupled channel, the parameterization.

$$
\mathrm{S}=\eta \mathrm{e}^{2 i \delta}=\cos \rho \mathrm{e}^{21 \delta}=\lambda^{2} \mathrm{e}^{21 \delta}
$$

can be used. The range of $\delta$ is $0 \leqq \delta<\pi$; the elasticity $\eta, \cos \rho$, or $\lambda^{2}$ is restricted by the unitarity condition $0 \leqq \eta=\cos p=\lambda^{2} \leqq 1$.

For the case of coupled channels, a common parameterization is ${ }^{2}$

$$
\left(\begin{array}{ll}
S_{11} & S_{12} \\
S_{21} & S_{22}
\end{array}\right)=\left(\begin{array}{ccc}
\cos \rho_{1} \cos 2 \varepsilon \mathrm{e}^{2 i \delta_{1}} & \mathrm{i} \sin 2 \varepsilon \mathrm{e}^{\mathrm{i}\left(\delta_{1}+\delta_{2}+\alpha\right)} \\
\mathrm{i} \sin 2 \varepsilon \mathrm{e}^{\mathrm{i}\left(\delta_{1}+\delta_{2}+\alpha\right)} & \cos \rho_{2} \cos 2 \varepsilon \mathrm{e}^{2 \mathrm{i} \delta_{2}}
\end{array}\right)
$$

In this parameterization, the choice of $\cos \rho_{1}$ and $\cos \rho_{2}$ is justified by the unitarity condition in Eq. (5). The range for the parameters is $0 \leqq \delta_{1}<\pi, \quad 0 \leqq \delta_{2}<\pi, \quad-\pi / 4<\varepsilon \leqq \pi / 4$, $0 \leqq \alpha \leqq \pi, 0 \leqq \rho_{1}<\pi / 2$, and $0 \leqq \rho_{2}<\pi / 2$, although not every choice of parameters allows one to find a (larger than 2 by 2 ) unitary matrix. When inelastic channels do not contribute, $\rho_{1} \rightarrow 0, p_{2} \rightarrow 0$, and $\alpha \rightarrow 0$, and the parameters are the nuclear bar phase shifts.

Another way of parameterizing is to make $\varepsilon$ complex,

$$
\left(\begin{array}{ll}
S_{11} & S_{12} \\
S_{21} & S_{22}
\end{array}\right)=\left(\begin{array}{lll}
\lambda_{1}^{2} \cos 2 \varepsilon^{\prime} & e^{2 i \delta_{1}} & i \lambda_{1} \lambda_{2} \sin 2 \varepsilon^{\prime} e^{i\left(\delta_{1}+\delta_{2}\right)} \\
i \lambda_{1} \lambda_{2} \sin 2 \varepsilon^{\prime} & e^{i\left(\delta_{1}+\delta_{2}\right)} & \lambda_{2}^{2} \cos 2 \varepsilon^{\prime} e^{2 i \delta_{2}}
\end{array}\right)
$$

with

$$
\varepsilon^{\prime}=\varepsilon+i \phi
$$

The ranges for $\delta_{1}, \delta_{2}, \varepsilon$, and $\phi$ are $0 \leqq \delta_{1}<\pi, 0 \leqq \delta_{2}<\pi,-\pi / 4<\varepsilon \leqq \pi / 4$, and $\phi \geqq 0$ to parameterize a complex symmetric matrix. The unitarity conditions from Eq. (5) give

$$
\begin{aligned}
& \lambda_{1}^{2} \lambda_{2}^{2}+\left(\lambda_{1}^{4}-\lambda_{1}^{2} \lambda_{2}^{2}\right) \cos ^{2} 2 \varepsilon+\left(\lambda_{1}^{4}+\lambda_{1}^{2} \lambda_{2}^{2}\right) \sinh ^{2} 2 \phi \leqq 1, \text { and } \\
& \lambda_{1}^{2} \lambda_{2}^{2}+\left(\lambda_{2}^{4}-\lambda_{1}^{2} \lambda_{2}^{2}\right) \cos ^{2} 2 \varepsilon+\left(\lambda_{2}^{4}+\lambda_{1}^{2} \lambda_{2}^{2}\right) \sinh ^{2} 2 \phi \leqq 1
\end{aligned}
$$


By adding these two inequalities, we see that unitarity requires as a necessary condition $\lambda_{1}^{2} \lambda_{2}^{2} \leqq 1$. It does not, however, require $\lambda_{1}^{2}$ and $\lambda_{2}^{2}$ both to be smaller than unity. In fact, it is easy to find a case in which, for example, $\lambda_{1}>1$, so it is not possible to express the $\lambda$ 's as cosines of angles, as is done in Ref. 3, without loss of generality. In the absence of inelastic scattering, $\lambda_{1} \rightarrow 1$, $\lambda_{2} \rightarrow 1$, and $\phi \rightarrow 0$, and the nuclear bar phase shifts remain.

If the nuclear bar phase shifts in Eq. (2b) are complex $\left(\delta+i \rho_{1}, \delta_{2}+i \rho_{2}\right.$, and $\left.\varepsilon+i \phi\right)$, Eq. (2b) becomes identical to Eq. (8) with $\lambda_{1}=\exp \left(-p_{1}\right)$. Using this parameterization, values of $\lambda$ larger than unity are possible. In that case $\rho \leqq 0$. Because $\lambda_{1}^{2} \lambda_{2}^{2} \leqq 1$, we always have $\rho_{1}+\rho_{2} \geqq 0$. When there is no elasticity, all angles become real.

\section{REFERENCES}

1. H. P. Stapp, T. J. Ypsilantis, and N. Metropolis, "Phase-Shift Analysis of 310-MeV Proton-Proton Scattering Experiments," Phys. Rev. 105, 302 (1957).

2. R. A. Arndt, "Phase-Shift Representation for Nucleon-Nucleon Scattering Above Pion-Production Threshold," Rev. Mod. Phys. 39, 710 (1967).

3. R. A. Arndt and B. J. VerWest, "NN Scattering Analysis Below $850 \mathrm{MeV}$ : A Status Report," Virginia Polytechnic Institute and Texas Agricultural and Mechanical University report DOE/ER/05223-29. 
Printed in the United States of America A vailable from

National Technical Information Service

US Department of Commerce

5285 Port Royal Road

Springfield, VA 22161

Microfiche $\$ 3.50(\mathrm{~A} 01)$

\begin{tabular}{|c|c|c|c|c|c|c|c|c|c|c|c|}
\hline Page Range & $\begin{array}{c}\text { Domestic } \\
\text { Price } \\
\end{array}$ & $\begin{array}{c}\text { NTIS } \\
\text { Price Code } \\
\end{array}$ & Page Range & $\begin{array}{c}\text { Domestic } \\
\text { Price } \\
\end{array}$ & $\begin{array}{c}\text { NTIS } \\
\text { Price Code } \\
\end{array}$ & Page Range & $\begin{array}{c}\text { Domestic } \\
\text { Price }\end{array}$ & $\begin{array}{c}\text { NTIS } \\
\text { Price Code } \\
\end{array}$ & Page Range & $\begin{array}{c}\text { Domestic } \\
\text { Price } \\
\end{array}$ & $\begin{array}{c}\text { NTIS } \\
\text { Price Code } \\
\end{array}$ \\
\hline $001-025$ & $\$ 5.00$ & $\mathrm{~A} \cup 2$ & $151-175$ & $\$ 11.00$ & A08 & 301325 & 517.00 & A 14 & $451-475$ & $\$ 23.00$ & $\mathrm{~A} 20$ \\
\hline $026-050$ & 6.00 & $\mathrm{~A} 03$ & $176-200$ & 12.00 & $\mathrm{~A} 09$ & $326-350$ & 18.00 & A 15 & $476-500$ & 24.00 & A21 \\
\hline $051-075$ & 7.00 & $\mathrm{~A} 04$ & $201-225$ & 13.00 & A 10 & $351-375$ & 19.00 & A 16 & $501-525$ & 25.00 & A 22 \\
\hline $076-100$ & 8.00 & A05 & $226-250$ & 14.00 & A11 & $376-400$ & 20.00 & A 17 & 526.550 & 26.00 & A 23 \\
\hline $101-125$ & 9.00 & $\mathrm{~A} 06$ & $251-275$ & 15.00 & A 12 & $401-425$ & 21.00 & A 18 & 551.575 & 27.00 & A 24 \\
\hline 126.150 & 10.00 & $\mathrm{~A} 07$ & $276-300$ & 16.00 & A 13 & $426-450$ & 22.00 & A 19 & 576.600 & 28.00 & A 25 \\
\hline
\end{tabular}

